\title{
FINANÇAS PÚBLICAS NA AMAZÔNIA: ALTERNATIVAS TERRITORIAIS PARA MAIOR AUTONOMIA DE BREVES, NO MARAJÓ'
}

Rodrigo Portugal ${ }^{2}$

Moisés Sarraf ${ }^{3}$

\section{INTRODUÇÃO}

No federalismo, a autonomia dos governos locais é um dos princípios a serem resguardados, pois é a partir dela que os territórios se governam por seus próprios meios e ofertam serviços públicos condizentes com os anseios da sociedade.

Em federaçóes centralizadas, como a brasileira, a maioria dos municípios depende, do ponto de vista fiscal, das transferências intergovernamentais, o que causa menor autonomia, tanto nas receitas, visto que há menor estímulo a aferir tributação própria, quanto nas despesas, uma vez que boa parte dos recursos transferidos são vinculados a funçôes orçamentárias predeterminadas, como saúde ou educação, reduzindo o raio de escolha da administração municipal.

Esse é o exemplo de Breves, município localizado na região do Marajó, no Pará, estado da Amazônia brasileira, localizado entre duas das maiores capitais da região, Belém (Pará) e Macapá (Amapá), e um importante entreposto na rota fluvial entre o rio Amazonas e o estuário do rio Pará. O município teve forte presença recente do setor madeireiro, pode ser acessado por via fluvial ou aérea e totaliza um contingente populacional de mais de $100 \mathrm{mil}$ pessoas, que demandam serviços públicos do poder local, pressionando por maior autonomia.

Este texto busca propor alternativas para uma maior autonomia nas receitas e despesas públicas de Breves, sugerindo, sob a perspectiva territorial, um modo como o município pode elevar sua autonomia política e de suas finanças públicas.

\section{TERRITÓRIO DE BREVES}

Para o escopo deste texto, território é o espaço (infraestrutura e meio ecológico) adicionado da sua dinâmica de uso pelos agentes, sejam empresas, pessoas ou instituiçóes, algo que Santos

1. DOI: http://dx.doi.org/10.38116/brua22art5

2. Pesquisador associado na Diretoria de Estudos e Políticas Regionais, Urbanas e Ambientais (Dirur) do Ipea; e economista na Superintendência do Desenvolvimento da Amazônia (Sudam).

3. Analista I do Instituto do Patrimônio Histórico e Artístico Nacional (Iphan). 
(1994) denominou de "território usado". Nesse sentido, no Brasil, as receitas próprias de um município, que dão base para as despesas autônomas, provêm do território. Isso ocorre porque os dois elementos que geram os principais tributos municipais, o Imposto sobre a Propriedade Territorial Urbana (IPTU) e o Imposto sobre Serviços (ISS), são o imóvel urbano e a prestação de serviços locais, respectivamente. Em ambos, a arrecadação é obtida sobre fatores locais de uso do território, seja de forma econômica ou patrimonial.

Desse modo, as transferências devolutivas, uma tributação gerada no município, mas arrecadada pelos governos estadual e federal e devolvidas em cotas-parte, seguem a mesma linha. As transferências do Imposto sobre Circulação de Mercadorias e Serviços (ICMS), do Imposto Territorial Rural (ITR) e do Imposto sobre a Propriedade de Veículos Automotores (IPVA) são cobradas sobre a economia e a propriedade local. Logo, iniciativas que envolvam as transferências devolutivas, incrementando a arrecadação tributária municipal, também passam pelo território.

Quanto à economia, a cidade de Breves foi um dos polos de produçấo madeireira na Amazônia durante o século XX, inclusive com proeminência nacional. Ainda em 1928, por exemplo, Andrade (1994) fez referência à madeira extraída na região, quando citou, na obra Macunaíma, uma "mesa de jacarandá esculpido arranjada com louça branco-encarnada de Breves e cerâmica de Belém (...)”.

Entre os anos 1970 e 1980, com a ida de grandes firmas madeireiras para a Amazônia, o município se consolidou como um dos maiores produtores de madeira em tora do Brasil, criando uma infraestrutura que conectou a extração na floresta nativa à organização das toras, passando pelo corte nas serrarias até o embarque em portos próprios para o exterior ou para Belém ou Macapá, a depender do que fosse considerado mais vantajoso. A concentração no setor madeireiro, acrescida do baixo nível de beneficiamento - da mesma maneira como ocorre com outros produtos de base extrativista -, acabou por fragilizar a economia de Breves, assim como foi uma forma de favorecimento dos setores oligárquicos que exploram os recursos naturais e o trabalho da população local.

O setor madeireiro se baseou no regime intensivo de mão de obra, o que colaborou para tornar a região populosa. Atualmente, são cerca de 100 mil habitantes, um número elevado, considerando a concentraçáo populacional nas capitais da região Norte, apesar de ser uma cidade sem conexão terrestre, apenas fluvial e aérea. Metade dessa população é ribeirinha, vive espalhada em comunidades no vasto território de abrangência do município, o que contraria a noção idílica de uma Amazônia despovoada. A maioria deles não possui a titulação da terra e, mesmo com o esforço de regularização fundiária (Ipea, 2015, p. 70), o fato restringe a cobrança do ITR e IPTU.

O contingente e o espraiamento populacional também são explicados pelo ciclo da borracha. Apesar do título de cidade madeireira, no século XIX, quando o uso do látex chegou a grandes proporçóes, Breves se tornou um dos principais produtores de borracha, a partir de relaçôes de trabalho servil com a incorporação dos descendentes de povos indígenas e, por fim, com as migraçóes nordestinas, o que na literatura amazônica foi chamado de "aviamento", a servidáo por dívidas.

O naturalista e escritor norte-americano William Edwards, na década de 1840, durante uma viagem à região, definiu Breves como "uma das pequenas cidades que cresceram desde a ativa demanda por borracha, a qual o distrito circundante produz vasta quantidade" (Edwards, 1861, p. 88). Em fins do mesmo século, o naturalista Herbert Smith descreveu a 
região como "um dos mais importantes distritos da borracha, onde centenas de seringueiros são empregados para coletar e preparar a goma bruta" (Smith, 1879, p. 82).

Dessa forma, pessoas migraram e se consolidaram a partir do comércio das rotas fluviais, da indústria madeireira e da extração de látex, facilitando a circulação de povos e culturas e ajudando a produção de identidades plurais, reunindo "traços indígenas, negros escravos, fugitivos quilombolas, nordestinos e estrangeiros como portugueses, judeus, turcos e norte-americanos" (Sarraf-Pacheco, 2010, p. 98).

Outro traço marcante do território brevense que influi na arrecadação e na despesa pública é o recorte fluvial, uma vez que o Marajó é o maior arquipélago marítimo fluvial do mundo, região que ainda pode ser subdividida em duas: Marajó dos Campos e Marajó das Florestas, esta última onde se situa o município de Breves (Sarraf-Pacheco, 2010). Na primeira, que tem Soure como cidade principal, a vegetação predominante é mais baixa, com áreas alagadas, próprias para o pasto e para a criação de búfalos. Na segunda há predominância da vegetação de mata fechada e de grandes rios, sendo importante ressaltar que, no município, não existem terras indígenas, mas, desde 2005, o governo federal, visando à proteção dos modos de vida e a cultura das populaçóes tradicionais, instituiu a Reserva Extrativista (Resex) do Mapuá, de onde é extraída boa parte da madeira certificada. Há, inclusive uma divergência histórica sobre qual seria a cidade com maior importância política, econômica e cultural no Marajó, se Breves ou Soure.

A configuração geográfica dos rios faz vigorar na cidade o que pode ser chamado de uma hidropolítica, relaçôes econômicas e políticas que se tornam eixos centrais na realidade regional. Como a principal forma de transporte de mercadorias, insumos e pessoas é a fluvial, empresas de navegaçáo se tornam imprescindíveis, garantindo vantagens econômicas e formando grupos que atuam no setor de serviços e comércios, como supermercados, estâncias e postos de combustíveis, por exemplo. Os proprietários dessas empresas, por sua vez, quando náo se tornam políticos (vereadores e prefeitos), financiam candidaturas, ocupando, assim, de um modo ou de outro, cargos no Executivo municipal e até mesmo no Legislativo estadual. Os proprietários de embarcaçôes, portanto, formam a elite econômica e política da região, consolidando o ciclo da hidropolítica - e quaisquer iniciativas de construçáo de outros modais, como aérea, precisa ser pactuada com esses agentes.

Dada essa configuração, Breves possui uma elite fluvial formada que se relaciona com o fluxo comercial da cidade. Quanto aos aspectos tributários, encontra-se uma baixa cota-parte de IPVA, dado que o imposto não cobre embarcaçóes, e se supóe um alto potencial de cota-parte de ICMS e ISS, pelo histórico fluxo comercial que já passou pelo ciclo da borracha e da indústria madeireira, envolvendo a regiáo e a conectividade com o rio Amazonas.

O mapa 1 mostra a localização de Breves e dos seus três distritos (Curumu, Antônio Lemos e São Miguel dos Macacos), todos eles constituídos ainda no século XIX, com populaçóes tradicionais que demandam serviços públicos do governo local e são caminhos e paradas naturais no furo de Breves, uma via do rio Amazonas até o estuário do Rio Pará. 
MAPA 1

Localização de Breves

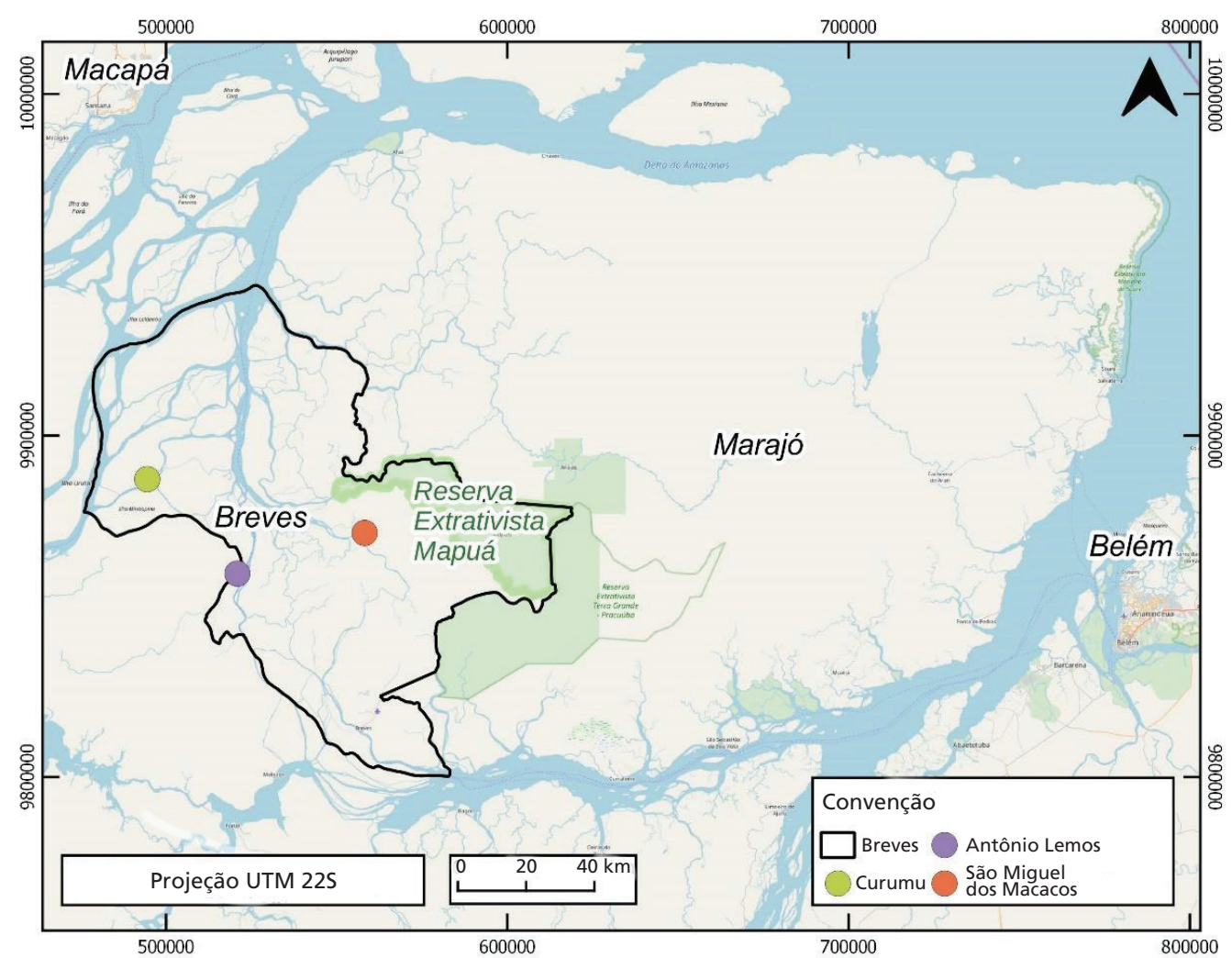

Fonte: IBGE.

Elaboração dos autores.

\section{AS RECEITAS EM BREVES}

No âmbito nacional, a tributação brasileira é derivada principalmente de impostos indiretos sobre a atividade econômica. Em comparação a outros países, que tributam majoritariamente a renda e o patrimônio, a nossa tributação tem características regressivas, como apontam Afonso, Soares e Castro (2013) e Gobetti e Orair (2016), entre outros autores. Dessa forma, seguindo a lógica brasileira, a tributação local deveria ser sensível à principal atividade econômica do município. Isso, porém, não foi percebido no histórico do setor madeireiro em Breves. A atividade não se converteu em impostos locais ao longo dos anos, prejudicando sua autonomia fiscal. O percentual de tributação em relação ao produto interno bruto (PIB) sempre girou em torno de 5\%, enquanto o valor adicionado pela indústria, que, no município, é sinônimo de atividade madeireira, oscilou de quase $40 \%$ para $10 \%$ em quinze anos (2002-2017), uma queda significativa, que mostra como a atividade econômica local é descolada dos tributos (gráfico 1).

A indústria madeireira não conseguiu induzir o aumento de serviços ligados ao ramo de modo que proporcionasse uma elevação de ISS - serviços de registros públicos, portuários, de navegação, seguros, apoio técnico, administrativo jurídico, contábil, de transporte, bancário, de manutenção e reparação de máquinas. Nada foi afetado significativamente pela extraçáo madeireira no local. Desse modo, as empresas complementares não se instalaram, e, logo, não se elevou o nível de arrecadação própria municipal. 


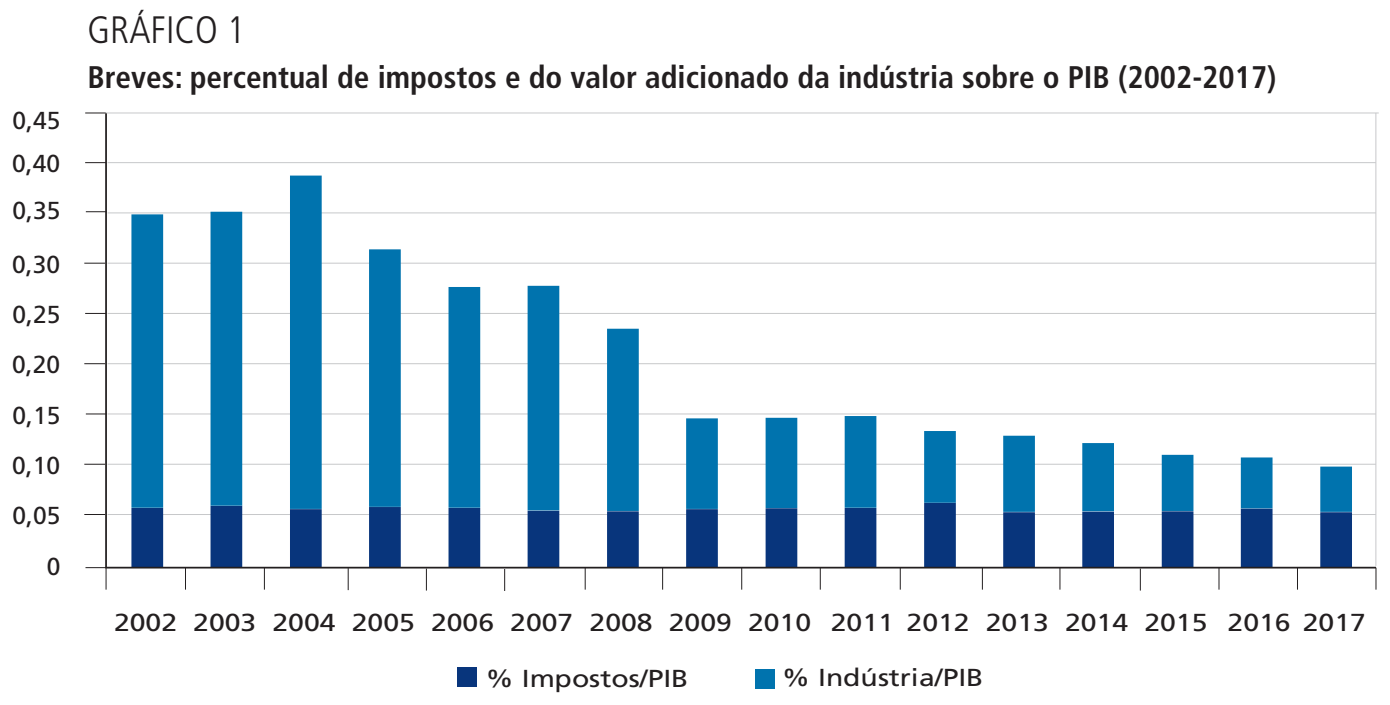

Fonte: IBGE.

Elaboração dos autores.

Os impostos sobre a propriedade também passaram ao largo dos cofres públicos. O IPTU sempre apresentou arrecadação mínima, uma característica dos municípios da região Norte, como apontou Carvalho Junior (2018). Em 2018, foi repassada pela União a quantia de R \$ 1.968,00, ${ }^{4}$ a título de ITR, uma transferência devolutiva que incide sobre a propriedade rural, em que $50 \%$ da arrecadação ficam com a União e $50 \%$ com o município e é fortemente afetada pela baixa regularização fundiária na regiáo.

No âmbito estadual, o ICMS, que incide sobre os desdobramentos de madeira (serrarias), sempre manteve uma arrecadação reduzida, o que proporciona um pequeno percentual de cota-parte transferida pelo governo do Estado, frustrando à expectativa de arrecadação gerada pelo fluxo comercial na cidade. Além disso, uma vez que, desde 1996, com a Lei Complementar nº 87/1996 (Lei Kandir), os produtos primários e industrializados semielaborados destinados ao exterior, principal destino da madeira de Breves, são isentos de ICMS, a indústria complementar que mais se desenvolveu localmente foi a de fabricação de vassouras, um setor de baixo valor agregado. O IPVA também apresentou um retorno pífio, e mesmo os impostos federais, como Imposto de Renda (IR) e Imposto sobre Produtos Industrializados (IPI), ou ainda as contribuiçôes sociais utilizadas para financiar a seguridade social, arrecadaram pouco sobre o setor. Assim, o aparato tributário brasileiro não se adequou em Breves e não conseguiu captar recursos proporcionais à principal atividade econômica do território (gráfico 1).

A explicação mais comum para esse quadro foi a baixa regularização da atividade, baseada em espoliação social e exploração ambiental a baixos custos de mão de obra, tecnologia e insumos rudimentares e reduzida incidência fiscal, o que acabou se tornando uma situação estrutural de pobreza. O Estado local não desenvolveu autonomia fiscal para atuar como regulador da atividade e tampouco para ser garantidor de rendas e serviços na região. A dinâmica territorial e produtiva se baseou fortemente na remessa de ativos ao estrangeiro sem tomada de decisão endógena e redistribuiçáo dos proventos entre os habitantes via tributação, o que consolidou os baixos indicadores sociais na região, os menores do Brasil.

4. Ver o Relatório Resumido da Execução Orçamentária (RREO), anexo 3 (6 bimestre de 2018), disponível em: <http://www. governotransparente.com.br/gestaofiscal/documentos/4400489?clean=false $>$. 
O declínio do setor se iniciou com as operaçōes realizadas em 2008 por órgãos ambientais do governo federal, que em parceria com a Polícia Federal (PF) fecharam inúmeras madeireiras ilegais no município, ocasionando protestos na cidade e uma baixa no nível de emprego. As açóes da PF faziam parte de uma estratégia mais ampla do governo federal, que buscava reduzir o desmatamento na região, atendendo à pressão internacional sobre a questáo ambiental. $\mathrm{Na}$ época, elites locais reagiram, anunciando o que poderia ser um desastre social, com o fim da atividade que mais gerava empregos na cidade. Ademais, a crise financeira mundial naquele mesmo ano também foi apontada como um fator que demarcou o declínio do setor. As grandes empresas que se instalaram no município entre os anos 1970 e 1980 encerraram suas atividades gradativamente. Alguns exemplos são a Madenorte, a Magebrás, a Mainardi e a Robco.

Os dados deixam claro o grande choque que as operaçôes ambientais causaram sobre o emprego na cidade. Em 2006, 2.500 pessoas estavam ocupadas no ramo enquanto, em 2017, esse número não chegou a 200, sendo possível perceber que os empregos migraram para o comércio varejista, principalmente as pequenas lojas e comércios locais. Vale ressaltar que, mesmo em um território cortado por rios, o núcleo urbano necessita de transporte terrestre, dada a precariedade do transporte público. Assim, o serviço de mototaxistas se tornou um dos que mais gerou trabalho na regiáo, fato similar em outras cidades da Amazônia e do Nordeste do Brasil.

Em relação aos empregos formais, o gráfico 2 mostra que houve uma migração de empregos para a administração pública, saúde e educação, esses dois últimos com um piso mínimo de gastos constitucionais e formas contemporâneas de manutenção dos empregos em situaçóes de queda estrutural da atividade econômica. Sem isso e sem os programas federais de transferência de renda, como o Bolsa Família, não haveria amortecedores sólidos sobre a renda no nível municipal em uma situação que já era de extrema pobreza.

\section{GRÁFICO 2}

Breves: pessoal ocupado total segundo a Classificação Nacional de Atividades Econômicas (CNAE)

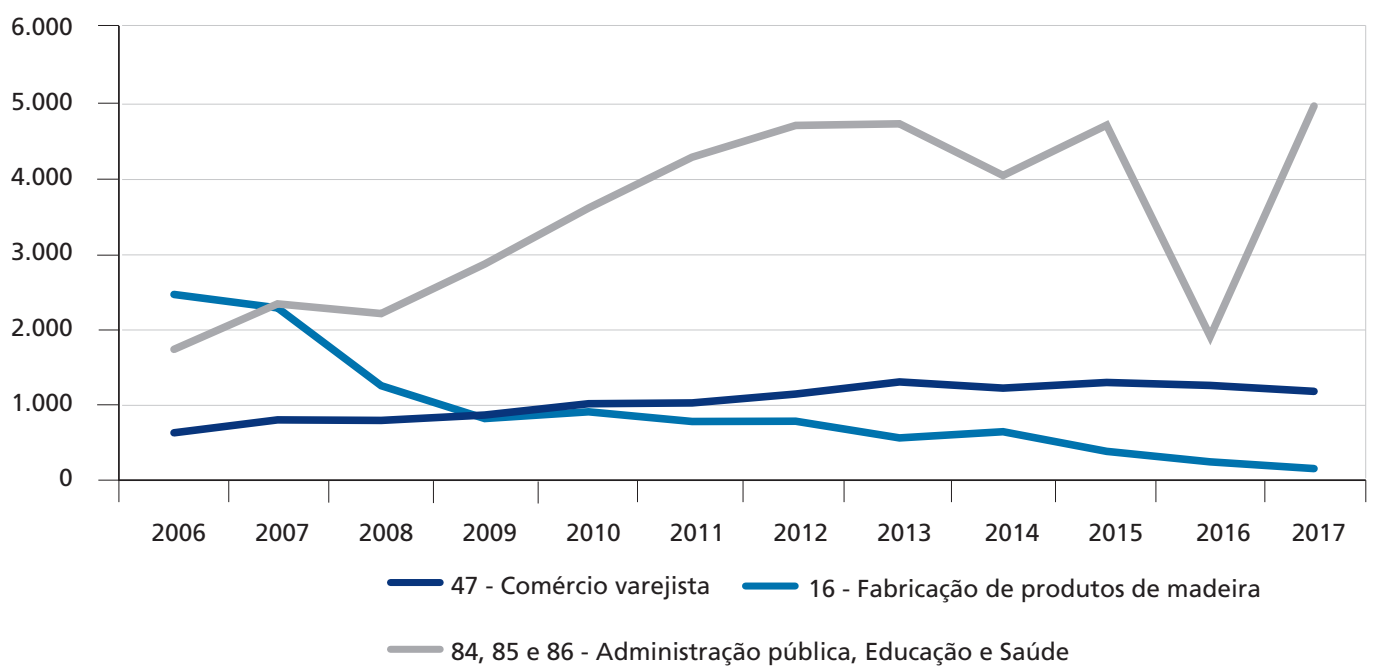

Fonte: Sistema IBGE de Recuperação Automática (SIDRA/IBGE). Elaboração dos autores.

Dada a fragilidade econômica em relação a prover tributação e autonomia fiscal, o município depende sobretudo das transferências intergovernamentais, entre as quais se destacam os recursos do Fundo de Manutenção e Desenvolvimento da Educaçáo Básica 
e de Valorização dos Profissionais da Educação (Fundeb), um fundo coordenado pelo governo federal cujas fontes de receita são oriundas de nove tributos diferentes, de todos os níveis federativos. A característica básica do fundo é o vínculo do seu gasto com despesas relacionadas à educação, o que diminui o raio de escolha da administração pública local.

Entre 2017 e 2019, ${ }^{5}$ o Fundeb representou 72\% da receita corrente líquida (RCL) do município, enquanto o Fundo de Participação dos Municípios (FPM), uma transferência intergovernamental de caráter redistributivo que não possui vinculação de gastos e que fica fora da influência municipal quanto aos valores, representou $21 \%$. Os tributos que poderiam elevar a arrecadação de acordo com determinado esforço local tiveram percentuais reduzidos, como a cota-parte do ICMS, 5\%, e a receita tributária própria, apenas $6 \%$.

Isso significa dizer que o esforço municipal para aumentar sua autonomia quanto às receitas passa pelo aumento da arrecadação de ISS e IPTU pela prefeitura e do ICMS pelo estado, o que demanda, além de maiores capacidades tecnológicas e administrativas na cobrança, setores produtivos que induzam serviços complementares no território, algo que a indústria madeireira nunca fez. O que se vislumbra em Breves é uma economia estagnada que sobrevive dos serviços públicos, principalmente no setor educacional, que forma mão de obra e qualifica as pessoas, mas estas não são absorvidas por setores produtivos de maior valor adicionado, inexistentes no município ou na região. A solução dos formados é migrar ou se empregar no comércio e na administração pública.

Assim, dado o arcabouço tributário e federativo brasileiro, o critério produtivo continua a ser a melhor forma de elevar as receitas próprias e a autonomia local, mas os setores precisam ser adequados ao território, o que em Breves significa:

- adequação ao transporte fluvial;

- preservação da mata nativa e regularização fundiária; e

- intensivo em mão de obra, para absorver o contingente vulnerável desde o colapso da indústria madeireira.

\section{AS DESPESAS POR FUNÇÃO}

Como as receitas do município são fortemente vinculadas às transferências do Fundeb, é fácil supor que a educação é a função orçamentária com maiores despesas executadas. Entre janeiro de 2017 e outubro de 2019, 55\% dos valores pagos pelos cofres públicos locais foram direcionadas para essa rubrica, entre pagamento de professores - o maior gasto -, manutenção de escolas e outros serviços. É maior que a saúde (20\%), que conta com um hospital regional de referência, inaugurado em 2010, para atender a microrregiáo do furo de Breves. Maior também que a administração pública, responsável pela gestão de um grande território formado por ilhas, comunidades, rios e um relativamente populoso núcleo urbano. E, por fim, maior ainda que o urbanismo, função última de todos os municípios. O gráfico 3 mostra essa proporção.

O maior gasto com educação representou uma elevação dos indicadores municipais. Segundo o índice de desenvolvimento da educação básica (Ideb), que leva em conta fatores como a taxa de rendimento escolar (aprovação), o gasto vem surtindo efeito, pois, em 2007

5. Ver o RREO, anexo 3 (6 bimestre de 2017, 2018 e 5o bimestre de 2019), disponível em: <http://www.governotransparente. com.br/gestaofiscal/documentos/ 4400489 ?clean=false $>$. 
o índice era de 2,1, passando para 3,5 em 2017, entre os alunos do $4^{\circ}$ ano e $5^{\circ}$ ano, e saindo de 3,1 para 3,7 entre os alunos do 8 - ano e $9^{\circ}$ ano.

GRÁFICO 3

Breves: despesas pagas entre jan./2017 e out./2019

(Em \%)

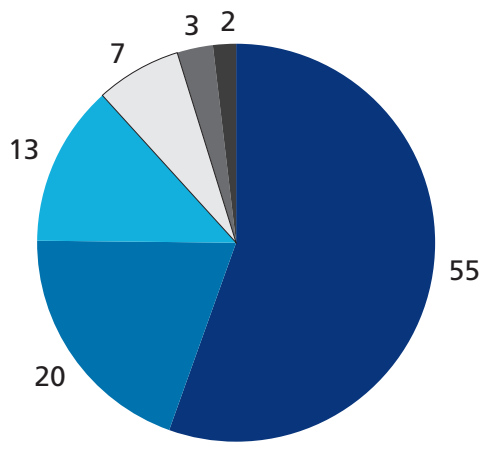

$\begin{array}{lll}\text { Educação } & \text { Saúde } & \text { Administração } \\ \text { Urbanismo } & \text { Assistência social } & \text { Outros }\end{array}$

Fonte: RREO (6o bimestre de 2017, 2018 e 50 bimestre de 2019).

Elaboração dos autores.

Apesar dos avanços e do aumento do indicador, o Ideb ainda é um dos mais baixos do Brasil, o que demonstra que o processo de educação é lento, gradual e aprofundado pelas desigualdades regionais no país.

As despesas mostram funções relevantes como a saúde e a educação, com fortes transferências vinculadas. A saúde, por exemplo, recebe recursos do Fundo Nacional de Saúde (FNS) para operacionalização do Sistema Único de Saúde (SUS), um vultoso valor na maioria dos municípios brasileiros. Funções sem as mesmas transferências federativas, que deveriam ser financiadas pela arrecadaçáo própria e suprir as demandas territoriais, ainda são, no entanto, incipientes.

A autonomia quanto às despesas chegou a despontar nas leis orçamentárias anuais (LOAs) entre 2017 e 2019, com previsão de gastos em segurança pública, transporte e organização agrária, porém acabou não sendo efetivada. É alarmante não haver gastos previstos nas LOAs com gestáo ambiental em uma cidade encravada na maior floresta tropical do mundo (Amazônia) e em uma área de preservação ambiental (APA) estadual, como o Marajó. Da mesma forma, é um absurdo não se prever gastos com saneamento básico em uma região com os menores indicadores do país e nem se elevar as despesas em assistência social em um espaço de grande vulnerabilidade social.

A questão da autonomia também passa pela adequação ao território, por meio de iniciativas conjuntas com outros níveis governamentais que podem ser norteadas pelos governos locais. Falar de transporte em Breves é falar sobre estrutura hidroviária, que requer um nível de investimentos que o município não suporta, mesmo que eleve sua autonomia fiscal. Daí a relevância dos investimentos estaduais e federais. Com o declínio do setor madeireiro, por exemplo, os portos privados das antigas madeireiras, como a Madenorte, estão em estado de abandono. Quem enxerga a possibilidade de utilização é o poder local, por meio dos vereadores ou parlamentares estaduais e federais ligados à regiáo, negociando investimentos diretos com o governo federal, na figura do Ministério da Infraestrutura ou do Ministério 
do Desenvolvimento Regional, ou por emendas parlamentares para operacionalização de uma estrutura portuária e náutica mais adequada.

No âmbito estadual, o governo do estado anunciou a construção de terminais hidroviários nos municípios do Marajó, com investimentos previstos de cerca de $\mathrm{R} \$ 750 \mathrm{mil},{ }^{6} \mathrm{um}$ valor baixo para a construção de um porto de maior estrutura em um município de 100 mil habitantes. Seria necessário que houvesse pressão local para construção de infraestruturas além de trapiches, com possibilidade de atraque de navios, balsas e embarcaçóes de pequeno e médio porte, com rotas regulares de transporte humano e de mercadorias em vários pontos do território. A organização dos fluxos (horários, preço e rotas regulares urbanas e interurbanas) enaltece a centralidade de Breves no sentido de consolidar o movimento de comércios vindos do rio Amazonas, dos municípios ao redor e das ilhas adjacentes, mas cabe ao governo local desempenhar a autonomia política, que vai além da fiscal, tanto no sentido de pressionar a realização da despesa quanto no de quebrar as estruturas da hidropolítica.

$\mathrm{Na}$ segurança pública ocorre fato similar, no qual a autonomia tem que ser exercida a partir de cooperação. A competência constitucional de manutenção das polícias militar e civil e do arcabouço judiciário é estadual e federal, mas o desdobramento da violência é local. $\mathrm{Na}$ imprensa, são comuns denúncias sobre casos de prostituição infantil e assaltos a embarcações, sobretudo na região do rio Tajapuru no furo de Breves, via de ligação entre as principais cidades da Amazônia oriental. Esses casos requerem uma ação supralocal, como nas operaçôes ambientais de 2008, que não foram duradouras, mas descortinaram uma situação bem presente, ainda que pouco divulgada, de que a ação ambiental, na Amazônia, é também uma ação policial.

A terra é uma questão delicada, e os conflitos armados pela posse do território são rotineiros em uma região com baixa titulação de terras - razão pela qual o IPTU e o ITR são pouco arrecadados no interior da Amazônia. A organização agrária pode aparecer na LOA como uma vontade legítima da administração local, mas só é operacionalizada como despesa de fato quando envolve o órgão estadual Instituto de Terras do Pará (Iterpa), o Instituto Nacional de Colonização e Reforma Agrária (Incra) e a Secretaria do Patrimônio da Uniâo (SPU), ambos federais, e os cartórios locais, assim como as polícias civil e militar e os órgãos ambientais. Não à toa, dois dos últimos três secretários de meio ambiente do Pará eram delegados ou advogados da União na área de patrimônio público.

Nesse sentido, um ordenamento territorial articulado cooperativamente pela administração local pode levar a uma tributaçáo mais qualificada dos impostos territoriais, inclusive com possibilidade de convênio com a Receita Federal para obter 100\% da arrecadação do ITR, num esforço que aumentaria as receitas e possibilitaria despesas mais autônomas.

Diante do exposto, é notória a vinculação das despesas com as receitas, o que reduz a capacidade de escolha municipal sobre o que gastar. Em certa medida, isso foi benéfico para melhorias nas ofertas de educação, mas restringiu gastos em áreas com amplas necessidades no território, como a gestão ambiental e o saneamento básico. Do mesmo modo, a autonomia tem os seus limites, uma vez que funçôes orçamentárias como segurança pública, transportes e organizaçáo agrária, preferencialmente devem ser exercidas de forma cooperativa, mas sempre referenciadas no território cujo representante-mor é o poder público local.

6. Disponível em: <https://agenciapara.com.br/noticia/15880/>. 


\section{ALTERNATIVAS PARA A AUTONOMIA}

A derrocada do setor madeireiro nos anos 2010 descortinou a possibilidade de mudança estrutural na atividade econômica do município, o que possibilita perspectivas de aumento da arrecadação própria. Vive-se uma transição para uma etapa de manejo mais sustentável e certificada de acordo com a preservação e com os dizeres legais e ambientais.

O gasto público se tornaria mais efetivo com o apoio ao manejo florestal, que traz consigo certa estrutura, como serviços de apoio à engenharia florestal e agronômica e suporte contábil e jurídico aos empreendimentos. A simples organizaçáo de todo esse processo já vislumbra o aumento da arrecadação do ISS, uma vez que as atividades-meios são uma das principais fontes de recursos do imposto. Uma questão relevante, no entanto, é que essas atividades precisam estar instaladas no município, o que significa uma menor dependência procedimental de Belém ou Macapá, propiciado oportunidades ao corpo técnico formado pelos cursos locais de graduaçáo e pós-graduação. O preconceito e a incapacidade material necessitam ser deixados de lado definitivamente.

A educação e a saúde avançaram, mesmo que lentamente, financiadas pelas transferências intergovernamentais, e podem ser um fator de impulso para o município. Breves possui 253 escolas de ensino fundamental, além de polos dos institutos federais, faculdades particulares e um campus da Universidade Federal do Pará (UFPA). São instituiçôes que podem se tornar centros para o desenvolvimento de técnicas de manejo das culturas extrativas. Para tanto, seria necessário atrair os cursos de tecnologia em madeira, engenharia florestal, agronomia e direito para o município, que já conta com administração, contábeis e gestão ambiental, segundo os dados de 2017 do Instituto Nacional de Estudos e Pesquisas Educacionais Anísio Teixeira (Inep) sobre concluintes do ensino superior. ${ }^{7}$

A internalização da cadeia produtiva possibilita aos agentes locais se sentirem mais autônomos na tomada de decisôes, retirando o caráter exógeno do Estado e das políticas públicas. A educação é um meio para se alcançar esse objetivo, assim como, ao mesmo tempo, é um fim, pois o município já é uma centralidade na oferta de serviços educacionais. O desafio é elevar a qualidade, aproveitando o centenário fluxo de pessoas na regiáo.

As alternativas não se propóem como substitutas ao setor madeireiro, mas surgem como opçóes de apostas para fazer o futuro. O governo do estado anunciou, em fins de 2019, a instalação de um distrito industrial em Breves, ${ }^{8}$ uma iniciativa que pode aumentar o comércio e a demanda por combustíveis, de forma a balancear a redução de ICMS que os incentivos fiscais propóem e, consequentemente, elevar a cota-parte que o município recebe. Os setores incentivados seriam: extração de madeiras e essências; alimentos; móveis e produtos de açaí; e construção civil. Como vantagem, é apontado o desenvolvimento do setor de comércio e serviços no município.

A crítica que se faz é a reediçáo da bizantina ideia de atraçáo de investimentos de outras localidades, como Belém e Sáo Paulo, que passam por intensos movimentos de desindustrialização, ou do exterior, cujo maior investidor atual é a China. A história brasileira de políticas de desenvolvimento regional a partir dessa matriz mostrou que as iniciativas tiveram pouco envolvimento territorial na Amazônia, não alimentando processos

7. Informação disponível em: <http://portal.inep.gov.br/inep-data>. Acesso em: 20 maio 2020.

8. Guia do investidor em Breves. Disponível em: <https://bit.ly/2ZluvRu>. Acesso em: 22 maio 2020. 
autônomos. Logo, a ideia é não persistir no erro, mas, sim, apostar em uma estratégia mais pragmática, com fulcro na história do território.

Utilizar os ativos da floresta é uma tônica secular na Amazônia e, nesse contexto, a Resex do Mapuá se descortina como uma oportunidade. Sempre houve conflito entre os grandes madeireiros e a comunidade extrativista sobre a propriedade da terra, o que foi, pelo menos institucionalmente, apaziguado com a criação da unidade de conservaçáo. Hoje, os moradores buscam alternativas de renda, entre as quais o turismo de base comunitária (Magalhães, 2014), uma das bases de tributação do ISS.

Amaral e Rodrigues (2018) mostram que a atividade madeireira fazia parte da rotina das grandes serrarias e das comunidades extrativistas da reserva, nas quais o açaí, o palmito, as sementes e as essências ainda fazem parte das tradiçôes locais e são uma expertise que precisa ser mais bem aproveitada. Os moradores da reserva, assim como dos distritos, têm como atividade tradicional a extração dos frutos e óleos, comercializados na sede do município e revendidos a empresas exportadoras. Essa rede comercial ventila a possibilidade de uma agroindústria local de beneficiamento, articulada com os concluintes de curso superior. Como uma atividade industrial, a agroindústria, a priori, tem maior potencial de arrecadaçáo do IPI, um tributo federal que retorna ao município em forma de FPM. Além disso, também eleva a arrecadação de ICMS.

A ResexMapuá está situada no município, que é recortado por ilhas e com quase metade da população ribeirinha. Assim, é imprescindível modelos de gestão de serviços públicos direcionados a esses distritos, considerando as demandas de suas populaçóes, como o transporte fluvial e a impreterível necessidade de investimentos no setor. Urge o apoio ao setor naval de pequeno porte, que já existe na região e que utiliza, inclusive, a madeira nativa. Seria importante enxergar essa atividade dentro de um contexto urbano, entendendo-a como um modal cujo fluxo é similar ao de ônibus e carros nas grandes cidades ou metrópoles brasileiras.

O governo estadual anunciou tímidos investimentos, mas o fomento à infraestrutura fluvial tem mesmo de ser de interno. Melhorar canoas, rabetas, barcos e balsas passa por iniciativas da própria região, que já conta com expertise local, uma elite formada pela hidropolítica e um mercado que se adequa à renda do território, provê infraestrutura e viabiliza investimentos com distribuiçâo de renda. Em relação à tributaçấo, o aumento do fluxo naval legalizado leva à elevação de ISS.

O setor naval ligado à circulação é intensivo em mão de obra, e sua regularização e ordenamento podem ser o caminho para recuperaçáo dos 2 mil empregos formais realocados com a decadência do setor madeireiro. Além disso, cumpre o papel de atender à circulação de pessoas e mercadorias que as agroindústrias e empresas de manejo, articuladas com a educação, necessitam. Portanto, é necessário organizar o setor e desenvolvê-lo, analogamente às linhas urbanas e interurbanas rodoviárias.

Em síntese, o poder público deve reformular seu olhar sobre as populaçóes marajoaras, seus saberes e suas práticas, que são oriundas de longos processos de encontro entre diversas culturas. Dessa forma, com uma ampla pactuação, considerando efetivamente as demandas da população, bem como suas formas de existir, será possível elaborar políticas públicas que reflitam o que essas comunidades vislumbram para o futuro. A história extrativista, apontada neste texto, deve estar subsidiada pelo conhecimento produzido pelos centros científicos regionais. Contudo, é preciso ir além: o conhecimento deve implementar formas 
de inovação tecnológica que garantam a verticalização da produção, bem como a efetividade de investimentos públicos para trilhar o caminho da autonomia, não só nas finanças públicas mas também nas decisôes territoriais.

Por fim, para que todo esse processos se concretize é preciso que açôes governamentais sejam autônomas e cooperativas, alinhando município, estado e União, mas mantendo o protagonismo da população. Historicamente, ciclos econômicos se sucederam na regiáo, relegando ao sujeito marajoara o lugar de mão de obra barata para a extração de matéria prima e beneficiamento de produtos acabados em áreas exteriores ao Marajó. Esses ciclos se exauriram e deixaram apenas o ônus socioambiental - um processo comum na região amazônica. É preciso que se estabeleçam tecnologias sociais garantidoras da cidadania plena, mecanismos de participação popular e fiscalização da aplicação de investimentos.

\section{CONCLUSÕES}

Este ensaio realizou um trajeto pelo histórico territorial e produtivo de Breves para propor alternativas que elevem a autonomia do governo municipal, tanto das receitas quanto das despesas públicas, sem descolamento dos fatores territoriais.

De uma região que passou pelos ciclos da borracha e da indústria madeireira sem avanço socioeconômico e, no último, sem aumento da arrecadação fiscal autônoma, Breves se tornou um município dependente das transferências intergovernamentais, principalmente do Fundeb, que direciona os seus gastos públicos para a educação. Apesar dos avanços nessa área, as demais, de grande demanda do território, continuam limitadas face à baixa autonomia fiscal. Entre as áreas mais carentes, destaca-se o saneamento, a assistência social, a gestão ambiental e a segurança pública, embora se reconheça que algumas delas são mais bem exercidas em cooperação com os demais entes federativos.

Conclui-se que, para uma maior autonomia fiscal, ainda é necessário investir nos setores econômicos, considerando a estrutura tributária brasileira. Sugere-se investimentos nos setores mais relacionados com o território, o que em Breves significa adequação ao transporte fluvial, preservação da mata nativa e ser intensivo em mão de obra. São eles: o manejo florestal da madeira, de modo a elevar a arrecadação de ICMS, que retorna em forma de cota-parte desde que o produto não seja enviado ao exterior; e a agroindústria de beneficiamento de sementes e essências, que arrecada ICMS, também desde que não exportada, possibilitando a arrecadaçáo de IPI, o qual volta ao município na forma de FPM. Os dois setores precisam estar interligados aos resultados dos gastos realizados em educação, uma vez que o município já formou administradores, contabilistas e gestores ambientais, mas ainda carece de formar engenheiros florestais, advogados, agrônomos e tecnólogos em madeira. Ademais, sugere-se o incentivo ao turismo de base comunitária e o urgente investimento em infraestrutura de transporte fluvial, ambos abrangidos pelo ISS, sendo o último intensivo em trabalho e que conecta todas as demais atividades.

\section{REFERÊNCIAS}

AFONSO, J. R.; SOARES, J. M.; CASTRO, K. P. de. Avaliaçáo da estrutura e do desempenho do sistema tributário brasileiro: livro branco da tributação brasileira. Brasília: BID, jan. 2013. (Texto para Discussão, n. 265).

AMARAL, V. S.; RODRIGUES, J. C. Reservas extrativistas na Amazônia: conflitos e interesses no processo de "construção" da ResexMapuá, Marajó, Pará. International Scientific Journal, v. 4, n. 13, 2018. 
ANDRADE, M. de. Macunaíma. São Paulo: Livraria Martins, 1994.

CARVALHO JUNIOR, P. H. Imposto Predial e Territorial Urbano (IPTU). In: FAGNANI, E. (Org.). A reforma tributária necessária: diagnóstico e premissas. 1. ed. São Paulo: Anfip; Fenafisco, 2018. p. 411-425.

EDWARDS, W. A voyage up the river amazon including a residence at Pará. Londres: John Murray, 1861.

GOBETTI, S.; ORAIR, R. Progressividade tributária: a agenda negligenciada. Rio de Janeiro: Ipea, abr. 2016. (Texto para Discussão, n. 2.190).

IPEA - INSTITUTO DE PESQUISA ECONÔMICA APLICADA. Observatório da funçáo socioambiental do patrimônio da Uniáo na Amazônia. Rio de Janeiro: Ipea, 2015. Disponível em: <http://repositorio.ipea.gov.br/bitstream/11058/7514/1/RP_Observat\%C3\%B3rio_2015. pdf>. Acesso em: 12 fev. 2020.

MAGALHÁES, A. P. F. Metodologia aplicada ao turismo de base comunitária em reservas extrativistas: valoração da atratividade turística de Resex - o exemplo de Mapuá, arquipélago do Marajó, Breves/PA. 2014. 124 f. Dissertação (Mestrado) - Universidade Federal do Pará, Belém, 2014.

SANTOS, M. O retorno do território. In: SANTOS, M.; SOUZA, M. A.; SILVEIRA, M. Território: globalização e fragmentação. São Paulo: Hucitec, 1994.

SARRAF-PACHECO, A. Encantarias afroindígenas na Amazônia marajoara: narrativas, práticas de cura e (in)tolerâncias religiosas. Horizonte, Belo Horizonte, v. 8, n. 17, p. 88-108, abr./jun. 2010.

SMITH, H. Brazil, the Amazons and the coast. New York: Charles Scribner's, 1879. 
